\title{
INFLUENCIA DO CLIMA ETICO SOBRE O COMPROMETIMENTO ORGANIZACIONAL DOS SERVIDORES DE UMA UNIVERSIDADE FEDERAL
}

\author{
THE INFLUENCE OF THE ETHICAL CLIMATE ON THE \\ ORGANIZATIONAL COMMITMENT OF THE SERVANTS IN A \\ FEDERAL UNIVERSITY
}

\author{
Alexandre Severino Pereira ${ }^{1}$ \\ Cristianne Pereira Cunha ${ }^{1}$ \\ Júlio Cesar Pompeu ${ }^{1}$
}

\section{Recebido em: 20/08/2015 Aceito em: 12/12/2015 \\ alexandre.severinop@gmail.com}

Resumo: O objetivo deste estudo foi verificar se o clima ético influencia o comprometimento organizacional de servidores de uma universidade federal. Para tanto foi realizada uma pesquisa exploratória de abordagem quantitativa em que foi aplicado um questionário a 248 servidores. 0 instrumento foi formulado a partir de escalas internacionalmente reconhecidas e continha assertivas sobre clima ético e comprometimento organizacional. Os dados obtidos foram analisados com recursos de estatística descritiva e multivariada. A utilização da técnica de Análise Fatorial permitiu identificar quatro dimensões do clima ético e três dimensões do comprometimento organizacional. Os resultados obtidos com a aplicação da técnica de Regressão Múltipla confirmaram a influência do clima ético sobre o comprometimento organizacional. A dimensão "Suporte" do clima ético apresentou influência positiva sobre o componente "Afetivo" do comprometimento organizacional. O clima ético denominado "Regras, Leis e Códigos" afetou as dimensões "Afetiva" e "Calculativa" do comprometimento. Por sua vez o clima ético "Sucesso e Eficiência" mostrou-se um antecedente de influência positiva sobre o comprometimento "Normativo".

Palavras-chave: Clima ético. Comprometimento organizacional. Universidade Federal. Servidores públicos. Estatística multivariada.

\begin{abstract}
The aim of this study was to verify if the ethical climate influences the organizational commitment of servants in a federal university. Thus an exploratory research of quantitative approach was conducted where a questionnaire was applied to 248 servants. The instrument was formulated from internationally recognized scales and contained assertive about ethical climate and organizational commitment. Data obtained were analyzed using the resources of the descriptive and multivariate statistic. Four dimensions of ethical climate and three dimensions of organizational commitment were identified. The application of Multiple Regression technique confirmed the influence of ethical climate on organizational commitment. The dimension "Support" of the ethical climate had a positive influence on the "Affective" component of the organizational commitment. The ethical climate called "Rules, Laws and Codes" affected the dimensions "Affective" and "Calculative" of the commitment. In turn the ethical climate "Success and Efficiency" they proved to be an antecedent of positive influence on the "Normative" commitment.
\end{abstract}

Keywords: Ethical climate. Organizational commitment. Federal University. Public servants. Multivariate statistics.

\footnotetext{
${ }^{1}$ Universidade Federal do Espírito Santo - UFES - Vitória - Espírito Santo - Brasil.
} 


\section{INTRODUÇÃO}

Nas últimas décadas foram feitos vários estudos a fim de identificar o nexo entre as organizações e seus integrantes, manifestos através de comprometimento organizacional. Esses estudos são justificados pela possibilidade de utilização do comprometimento organizacional como instrumento de previsão de comportamentos relevantes para a organização tais como o absenteísmo, rotatividade e desempenho, além de possibilitar a identificação de um modelo de comportamento que as organizações desejam (COHEN et al, 2003).

Outro tipo de comportamento desejável também pela sociedade como um todo, é o comportamento ético que coloca os indivíduos, frente a um dilema: se por um lado há regras baseadas em valores coletivos e universais, por outro existem sujeitos individualizados por uma sociedade que tem suas relações baseadas no mercado e na competição. Assim o coletivo que seria utilizado como parâmetro para a moralidade e para regular as relações sociais enfraquece (MENDES; ANDRADE, 2010).

Empregando uma definição ampla de ética no desenvolvimento do conceito de um ambiente de trabalho ético, a resposta, para um membro de uma organização, a pergunta socrática: "O que devo fazer?" seria respondida por ele mesmo com base no clima ético da organização (VICTOR; CULLEN, 1988). Assim o estudo do clima ético não é utilizado como instrumento para verificar o quão desenvolvida está uma organização no que concerne a ética e sim como uma ferramenta para diagnóstico e avaliação da tomada de decisão e do comportamento do indivíduo (CULLEN; PARBOTEEAH; VICTOR, 2003; MARTIN; CULLEN, 2006).

Pode-se perceber que tanto o comprometimento organizacional quanto o clima ético são fatores que influenciam a organização através da sua força de trabalho, considerada uma vantagem competitiva, e isto é fator diferencial para sobrevivência da organização no mundo competitivo e em constante mudança da atualidade (YENER; YALDITAN; ERGUN, 2012).

Este estudo tem como objetivo verificar se o clima ético influencia o comprometimento organizacional de servidores de uma universidade federal e, em caso positivo, avaliar como ocorre tal influência. Com esse propósito foi feita primeiramente uma revisão de literatura abordando os principais conceitos da temática e constatações de estudos anteriores. Na sequência foi descrita a metodologia envolvendo amostragem e procedimentos de coleta e análise dos dados. E por fim são apresentados e discutidos os resultados e as considerações finais do estudo.

\section{CLIMA ÉTICO}

O clima ético é um componente do clima organizacional (ELCl; ALPKAN, 2009) e foi definido como as percepções compartilhadas de como é o comportamento correto e como se deve lidar com as situações éticas em uma organização (VICTOR; CULLEN, 1987). Essa definição considera que o contexto organizacional exerce um papel essencial na decisão dos trabalhadores de se comportar de forma ética ou não (MAYER; KUENZI; GREENBAUM, 2009). 
O clima ético pode também ser definido como um tipo de clima de trabalho que reflete as políticas, procedimentos e práticas organizacionais que possuem consequências morais (MARTIN; CULLEN, 2006; MULKI; JARAMILLO; LOCANDER, 2008).

Para Treviño e Brown (2004) a maioria dos comportamentos não éticos no mundo organizacional são produtos do contexto em que ocorrem, ou seja, o ambiente de trabalho tem uma importante influência no comportamento ético dos trabalhadores. Corroborando com essa ideia, Victor

e Cullen (1988) apontam que as organizações são estruturas sociais que orientam os comportamentos éticos dos seus trabalhadores.

Sims e Kroeck (1994) e Schwepker (1999) observaram em seus estudos que os trabalhadores, quando sentem que os valores da organização em que trabalham estão em conflito com os seus próprios valores éticos, se identificam menos ou tem menor nível de comprometimento com a organização.

Dessa forma, conhecer os climas de vários subgrupos pode permitir aos gestores tomar as medidas adequadas para ter comportamentos mais éticos e uma melhor produtividade (WIMBUSH; SHEPARD; MARKHAM, 1997).

\subsection{Dimensões Teóricas e Empíricas do Clima Ético}

A teoria do clima ético de Victor e Cullen (1988) e a construção do questionário de clima ético foram parcialmente baseadas em perspectivas filosóficas, como a teoria do desenvolvimento moral de Kohlberg.

A tipologia teórica do clima ético é bidimensional e descreve os diferentes tipos de existentes nas organizações. A primeira dimensão refere-se ao critério ético utilizado numa tomada de decisão organizacional e está baseada em três categorias: egoísmo, benevolência e princípio (VICTOR; CULLEN, 1988). A segunda dimensão refere-se ao locus de análise que representa o grupo de referência usado para aplicar o critério ético às decisões organizacionais (VICTOR; CULLEN, 1988; CULLEN, PARBOTEEAH; VICTOR, 2003). Esta dimensão também possui três categorias: individual, local e cosmopolita.

Do cruzamento da matriz de três critérios éticos por três locus de análise originaram-se nove dimensões teóricas do clima ético que são apresentadas no Quadro 1, bem como suas respectivas descrições.

Estudos do CEPE [ISSN 1982-6729]. Santa Cruz do Sul, n. 42, p. 49-67, jan./jun. 2016. https://online.unisc.br/seer/index.php/cepe/index 
Quadro 1 - Nove dimensões teóricas do clima ético

\begin{tabular}{|c|c|c|c|}
\hline & Individual & Local & Cosmopolita \\
\hline Egoísmo & $\begin{array}{l}\text { Auto-interesse: o egoísmo, } \\
\text { neste nível, promove a } \\
\text { consideração } \\
\text { necessidades e preferências } \\
\text { do próprio indivíduo (por } \\
\text { exemplo, ganhos pessoais, } \\
\text { auto -defesa). O auto- } \\
\text { interesse pode ser definido } \\
\text { como o bem-estar físico, } \\
\text { prazer, poder, felicidade e } \\
\text { outros critérios que promovam } \\
\text { os interesses de um indivíduo. }\end{array}$ & $\begin{array}{l}\text { Lucro da organização: } \\
\text { devido ao fato de no locus de } \\
\text { análise local as decisões } \\
\text { éticas serem influenciadas } \\
\text { pelas crenças do grupo de } \\
\text { trabalho mais próximo, o lucro } \\
\text { da organização refere-se ao } \\
\text { contexto onde as decisões dos } \\
\text { indivíduos refletem os } \\
\text { melhores interesses da } \\
\text { organização (por exemplo, } \\
\text { vantagem estratégica). }\end{array}$ & $\begin{array}{l}\text { Eficiência: neste tipo de } \\
\text { clima, as decisões éticas } \\
\text { são influenciadas pelos } \\
\text { interesses sociais ou } \\
\text { econômicos gerais. }\end{array}$ \\
\hline Benevolência & $\begin{array}{l}\text { Amizade: baseada no critério } \\
\text { da benevolência e da } \\
\text { consideração pelas outras } \\
\text { pessoas, este tipo de clima } \\
\text { enfatiza os interesses dos } \\
\text { amigos, sem se referir ao } \\
\text { sentimento de pertencer } \\
\text { organizacional (por exemplo, } \\
\text { amizade, reciprocidade); }\end{array}$ & $\begin{array}{l}\text { Interesse de equipe: enfatiza } \\
\text { a consideração pelo coletivo } \\
\text { organizacional (por exemplo, } \\
\text { espírito de equipe); }\end{array}$ & $\begin{array}{l}\text { Responsabilidade social: } \\
\text { as decisões éticas são } \\
\text { influenciadas por fatores } \\
\text { externos que guiam o } \\
\text { comportamento } \\
\text { socialmente responsável; }\end{array}$ \\
\hline Princípio & $\begin{array}{l}\text { Moralidade pessoal: devido } \\
\text { ao fato de no locus de análise } \\
\text { individual os princípios serem } \\
\text { auto-escolhidos, é esperado } \\
\text { que, neste clima, cada um } \\
\text { seja guiado pela sua ética } \\
\text { pessoal; }\end{array}$ & $\begin{array}{l}\text { Regras e procedimentos da } \\
\text { organização: neste tipo de } \\
\text { clima ético, a fonte dos } \\
\text { princípios éticos derivam da } \\
\text { organização (por exemplo, das } \\
\text { regras e procedimentos); }\end{array}$ & $\begin{array}{l}\text { Leis e códigos } \\
\text { profissionais: neste tipo } \\
\text { de clima ético, a fonte dos } \\
\text { princípios transcende a } \\
\text { organização (por exemplo } \\
\text { sistema legal, } \\
\text { sindicatos). }\end{array}$ \\
\hline
\end{tabular}

Fonte: Adaptado de Victor e Cullen (1988); Elçi e Alpkan (2009).

Essas dimensões teóricas foram testadas empiricamente pelos autores e os resultados do estudo apontaram a existência de cinco tipos de clima ético (VICTOR; CULLEN, 1988). As cinco dimensões empíricas e as suas respectivas descrições são exibidas no Quadro 2.

Dentre essas dimensões empíricas de clima ético, Cullen, Parboteeah e Victor (2003) afirmaram que o clima Instrumental é o menos comum, enquanto por outro lado, o clima de Suporte tem sido indicado como de maior frequência. 
Quadro 2 - Cinco dimensões empíricas do clima ético

\begin{tabular}{|c|c|c|c|}
\hline & Individual & Local & Cosmopolita \\
\hline Egoísmo & \multicolumn{2}{|c|}{$\begin{array}{l}\text { Instrumental: neste tipo de clima, os atores percebem } \\
\text { que a sua unidade organizacional possui normas e } \\
\text { expectativas que encorajam a tomada de decisão ética a } \\
\text { partir de uma perspectiva egoísta. Os atores percebem } \\
\text { que o auto-interesse guia o comportamento, mesmo que } \\
\text { implique um possível detrimento de outros. }\end{array}$} & \\
\hline Benevolência & \multicolumn{2}{|c|}{$\begin{array}{l}\text { Suporte: neste clima, os atores percebem que as } \\
\text { decisões são e devem ser baseadas numa preocupação } \\
\text { constante pelo bem-estar dos outros. Estes percebem que } \\
\text { a preocupação ética existe para os outros dentro da } \\
\text { organização, bem como na sociedade no geral. É } \\
\text { percebido, também, que a preocupação e a consideração } \\
\text { pelos outros são apoiadas pelas políticas, práticas e } \\
\text { estratégias da organização através dos seus atores. }\end{array}$} & \\
\hline Princípio & $\begin{array}{l}\text { Independência (a moralidade } \\
\text { pessoal é o único constructo } \\
\text { que constitui este clima): neste } \\
\text { tipo de clima, os indivíduos } \\
\text { acreditam que devem agir de } \\
\text { acordo com as convicções } \\
\text { morais pessoais para a tomada } \\
\text { de decisão ética. Na } \\
\text { perspectiva da organização, as } \\
\text { decisões, com consequências } \\
\text { morais, devem enfatizar as } \\
\text { crenças pessoais } \\
\text { moralidade. }\end{array}$ & $\begin{array}{l}\text { Regras: neste clima } \\
\text { percebe-se que as } \\
\text { decisões } \\
\text { organizacionais são } \\
\text { guiadas por regras } \\
\text { locais ou padrões } \\
\text { fortes e persuasivos, } \\
\text { como os códigos de } \\
\text { conduta na } \\
\text { implementados } \\
\text { organização. }\end{array}$ & $\begin{array}{l}\text { Lei e código: neste clima, é } \\
\text { percebido que a organização } \\
\text { apoia a tomada de decisão } \\
\text { baseada nos princípios, em } \\
\text { códigos externos, como leis ou } \\
\text { códigos de conduta profissionais. } \\
\text { Estes códigos externos são } \\
\text { percebidos como orientadores da } \\
\text { tomada de decisão ética e do } \\
\text { comportamento } \\
\text { trabalhadores no contexto } \\
\text { organizacional. }\end{array}$ \\
\hline
\end{tabular}

Fonte: Adaptado de Victor e Cullen (1988) e Martin e Cullen (2006).

Em relação aos efeitos do clima ético nas organizações, o estudo de Mayer, Kuenzi e Greenbaun (2009) enumeraram diversos consequentes do clima ético constatados em estudos anteriores e indicaram três categorias: atitudes de trabalho, comportamento ético e diversos resultados éticos e organizacionais. Dentre os efeitos relacionados pelos autores, constam satisfação no trabalho, comprometimento organizacional, intenção de sair da organização, comportamentos éticos ou não éticos, julgamentos e tomada de decisão éticas e níveis de comunicação. A diversidade e os tipos de efeitos associados clima ético nas organizações revelam a amplitude desse campo de estudo, bem como sua importância.

Em função da proposta deste estudo, dentre os consequentes do clima ético organizacional registrados por Mayer, Kuenzi e Greenbaun (2009) destaca-se o comprometimento organizacional abordado a seguir. 


\section{COMPROMETIMENTO ORGANIZACIONAL}

O comprometimento organizacional é comumente definido como 0 interesse dos trabalhadores numa organização e sua conexão à mesma (MEYER; ALLEN, 1991, 1997; VALENTINE; GODKIN; LUCERO, 2002). Os empregados que estão comprometidos tendem a identificar-se com os objetivos e a desejar permanecer nas suas organizações (TSAI; HUANG, 2008).

A importância do estudo do comprometimento organizacional pode ser atribuída a vários aspectos: tanto os indivíduos quanto as organizações são afetados negativamente quando o comprometimento é baixo, ao passo que ambos são beneficiados quando ele é alto (RANDALL, 1987). Além disso, o comprometimento organizacional afeta a satisfação (HUNT; CHONKO; WOOD, 1985), o desempenho (MORRIS; SHERMAN, 1981) e a adaptabilidade organizacionais (ANGLE; PERRY, 1981), bem como os índices de absenteísmo (HAMMER; LANDAU; STERN, 1981) e rotatividade de funcionários (ABELSON, 1983).

Para estudar o comprometimento organizacional, Meyer e Allen desenvolveram o Modelo Tridimensional do Comprometimento Organizacional tomando como base semelhanças e diferenças que existiam nas várias teorias existentes à época (MEYER; ALLEN, 1984, 1991; ALLEN; MEYER, 1990).

Os autores identificaram três formas distintas de comprometimento organizacional: Afetivo, Normativo e Calculativo. O comprometimento Afetivo reflete uma ligação emocional ou envolvimento com organização, enquanto o Normativo é vivido como uma sensação de obrigação de permanência, e o Calculativo (ou de continuidade ou instrumental) envolve análise dos custos percebidos quando se avalia a opção de sair da organização. Duas das medidas de comprometimento deste modelo foram utilizados pela primeira vez em pesquisa publicada por Meyer e Allen (1984), e a terceira foi incluída no modelo posteriormente por Allen e Meyer (1990).

Meyer, Allen e Smith (1993, p. 3) exemplificaram o perfil do indivíduo em cada uma das dimensões: "empregados com forte comprometimento Afetivo permanecem na organização, porque eles querem; aqueles com comprometimento instrumental permanecem, porque eles precisam; e aqueles com comprometimento Normativo permanecem na organização, porque eles sentem que são obrigados".

Meyer et al. (2012) relataram que na última década, tem havido um aumento da utilização do Modelo Tridimensional do Comprometimento Organizacional fora da América do Norte. Os autores alertam que como efeito dessa difusão de estudos, as análises dos itens traduzidos podem ter produzido resultados mistos.

\section{CLIMA ÉTICO COMO ANTECEDENTE DO COMPROMETIMENTO ORGANIZACIONAL}

Estudos sobre a influência do clima ético sobre o comprometimento organizacional têm indicado que climas éticos positivos afetam positivamente o comprometimento organizacional dos empregados (BABIN; BOLES; ROBIN, 2000; HERNDON; FRAEDRICH; YEH, 2001; SCHWEPKER, 2001).

Estudos do CEPE [ISSN 1982-6729]. Santa Cruz do Sul, n. 43, p.49-67, jan./jun. 2016. https://online.unisc.br/seer/index.php/cepe/index 
Os resultados obtidos por Cullen, Parboteeah e Victor (2003) mostraram que os climas benevolentes estão positivamente relacionados com o comprometimento organizacional, enquanto os climas egoístas estão negativamente relacionados com o comprometimento. Os autores também encontraram uma relação positiva entre o comprometimento organizacional e os climas de princípio.

Esses autores ainda explicaram que (1) climas benevolentes influenciam positivamente o comprometimento organizacional, uma vez que encorajam o afeto positivo e uma maior ligação por parte dos membros da organização, já que percebem um ambiente de suporte; (2) climas de princípios afetam positivamente o comprometimento organizacional, ao passo que incentivam a internalização de valores e códigos de conduta, ou seja, os indivíduos que acreditam que a organização é guiada por esses mesmos códigos de conduta tendem a criar uma maior ligação com a empresa, e; (3) climas egoístas influenciam negativamente o comprometimento organizacional, a medida que a encorajam o auto-interesse dos indivíduos e da organização, o que pode levar a menores níveis de cooperação e coesão grupal e, consequentemente a um menor o comprometimento.

Os resultados obtidos por Tsai e Huang (2008) mostraram que: (1) o clima Suporte influencia positivamente o componente Normativo do comprometimento organizacional; (2) o clima Independência não influencia nenhum componente; (3) o clima de Regras influencia positivamente o componente Normativo; (4) o clima Instrumental influencia negativamente o componente Afetivo e o comprometimento organizacional em geral, mas apresenta uma influência positiva no componente de continuidade (Calculativo); e (5) o clima de Lei e Código foi o mais percebido, mas não foi detectado impacto sobre os componentes do comprometimento organizacional.

Erben e Guneser (2008) encontraram uma forte relação entre o clima ético e comprometimento Afetivo, além de uma relação moderada com o comprometimento Calculativo. Filipova (2009) observou que o clima ético benevolente teve uma influência positiva significativa sobre comprometimento organizacional, enquanto a influência do clima instrumental foi negativa.

\section{METODOLOGIA}

O principal objetivo deste estudo foi investigar a relação entre o clima ético e o comprometimento organizacional em uma universidade federal. Trata-se de um estudo exploratório com adoção de procedimentos técnicos de levantamento (survey) e análise estatística dos dados. Para tanto foram executadas as seguintes etapas de trabalho: revisão bibliográfica, amostragem, coleta e análise dos dados, apresentação e discussão dos resultados.

\subsection{Amostra}

A amostragem foi realizada por conveniência e foi composta de 248 servidores técnicoadministrativos em educação efetivos de uma universidade federal. Esta categoria de servidores foi escolhida com o objetivo de obter participantes que possuem tipos de atividades e ambientes de 
trabalho semelhantes. Por esse mesmo motivo não foram incluídos na amostra os servidores do Hospital Universitário vinculado à instituição e os professores.

Os participantes trabalhavam em 36 setores distribuídos em 4 campi da instituição. A maioria foi do sexo feminino (53,9\%) e nunca exerceu chefia $(58,9 \%)$. A idade média foi de 38 anos e a faixa de variação de 21 a 67 anos. A escolaridade variou de ensino fundamental até doutorado, sendo $58,5 \%$ com o título de especialista. Em relação ao tempo de serviço, a faixa de variação foi de 0 a 37 anos e a média de 10 anos.

\subsection{Coleta de Dados}

O instrumento de coleta de dados consiste de três seções - questionário de clima ético, escala de comprometimento organizacional e itens de dados gerais para caracterização da amostra, além de informações sobre o propósito da pesquisa e seus responsáveis e o compromisso de confidencialidade dos dados obtidos. O questionário completo continha um total de cinquenta e uma assertivas.

Na primeira seção, o questionário de clima ético utilizado foi proposto por Victor e Cullen (1988) e consiste de vinte e seis itens. As respostas são baseadas em uma escala de seis pontos do tipo Likert, variando de 1 - Completamente Falso a 6 - Completamente Verdadeiro.

Na segunda seção, o questionário de comprometimento organizacional utilizado foi proposto por Meyer, Allen e Smith (1993) e contêm dezoito itens, sendo seis itens para cada sub-escala (Afetivo, Normativo e Instrumental). A escala de respostas é do tipo Likert de sete pontos variando de 1 - Discordo Totalmente a 7 - Concordo Totalmente.

$\mathrm{Na}$ terceira seção foram incluídos itens para caracterização da amostra e que poderiam ser utilizadas como variáveis mediadoras nas análises. As questões se referiram ao sexo (gênero), idade, escolaridade, setor de trabalho, tempo de serviço e exercício de função (chefia).

\subsection{Análises}

A análise dos dados foi iniciada por uma fase exploratória, para verificar o atendimento dos pressupostos para aplicação das técnicas estatísticas pretendidas.

Não foram identificados valores extremos e dados perdidos (missing values), tendo em vista que foram utilizados somente questionário completamente respondidos pelos participantes.

Em relação à normalidade dos dados, todas as variáveis foram identificadas como não normais no teste Kolmogorov-Smirnov a um nível de significância de 5\%. No entanto Schumacker e Lomax (2004) defendem que curtose e assimetria entre +1 e -1 não impedem a aplicação de técnicas que pressupõem a normalidade dos dados. Dessa forma, verificou-se que os índices de curtose dos itens das escalas variaram de 0,695 a $-1,239$ e os de assimetria variaram de 0,983 a $-1,128$. Como apenas sete itens das escalas não se enquadram no intervalo e apresentaram índices próximos ao limite (+1 ou -1$)$, as análises foram realizadas. 
Após essa fase inicial, foram realizadas outras três etapas de análise dos dados: (1) Identificação de dimensões latentes (ou fatores) do clima ético e do comprometimento organizacional por meio da técnica de análise fatorial exploratória. O método de extração de fatores utilizado foi o de análise dos componentes principais com rotação Varimax. O número de fatores foi definido com base no critério da raiz latente (ou critério de Kaiser) e do gráfico de Scree. Em função do tamanho da amostra, as cargas fatoriais consideradas significantes foram aquelas maiores ou iguais a 0,4 , conforme Hair et al (2009); (2) Análise de confiabilidade das escalas completas e das dimensões obtidas com o uso do a de Cronbach; e (3) Análise da influência das dimensões de clima ético sobre os três componentes do compromentimento organizacional utilizando a técnica de análise de regressão linear múltipla.

Neste estudo os procedimentos estatísticos foram executadas com apoio do software SPSS (Statitical Package For The Social Sciences) - versão 19.

\section{RESULTADOS E DISCUSSÃO}

Os resultados deste estudo foram organizados conforme a sequência das etapas de análise indicadas na metodologia. Primeiro são apresentadas as dimensões do clima ético, em seguida os componentes do comprometimento organizacional, a análise de confiabilidade das escalas usadas e análise da influência do clima ético sobre o comprometimento.

\subsection{Dimensões do Clima Ético Organizacional}

Para identificar as dimensões do clima ético organizacional foi realizada uma análise fatorial exploratória com os vinte e seis itens do questionário. Da análise fatorial emergiram quatro dimensões ou tipos de clima ético, um a menos do que foi obtido por Victor e Cullen (1988). Cinco rotações foram necessárias para obter a melhor representação das informações e nove itens foram excluídos da análise por possuir cargas fatoriais cruzadas ou inferiores a 0,40. Na Tabela 1 são apresentados os resultados da análise fatorial dos itens do clima ético.

Estudos do CEPE [ISSN 1982-6729]. Santa Cruz do Sul, n. 42, p. 49-67, jan./jun. 2016. https://online.unisc.br/seer/index.php/cepe/index 
Tabela 1 - Resultados da Análise Fatorial do Clima Ético

\begin{tabular}{|c|c|}
\hline Fatores e Itens & $\begin{array}{l}\text { Cargas } \\
\text { Fatoriais }\end{array}$ \\
\hline \multicolumn{2}{|l|}{ Fator 1: Suporte (35,524\% da Variância) } \\
\hline Nossa principal consideração é o melhor para todos na organização. & 0,823 \\
\hline A maior preocupação é o bem-estar de todas as pessoas da organização. & 0,807 \\
\hline Nesta organização, as pessoas buscam o bem do outro. & 0,752 \\
\hline Nossa principal preocupação é sempre o que é melhor para a outra pessoa. & 0,682 \\
\hline \multicolumn{2}{|l|}{ Fator 2: Regras, Leis e Códigos (12,757\% da Variância) } \\
\hline $\begin{array}{l}\text { Nesta organização, espera-se que as pessoas sigam rigorosamente as normas legais ou } \\
\text { profissionais. }\end{array}$ & 0,855 \\
\hline $\begin{array}{l}\text { Espera-se que as pessoas se sujeitem as leis e normas profissionais, acima de outras } \\
\text { considerações. }\end{array}$ & 0,811 \\
\hline É muito importante seguir rigorosamente as regras e procedimentos da organização. & 0,769 \\
\hline Espera-se que todos respeitem as regras e procedimentos da organização. & 0,703 \\
\hline \multicolumn{2}{|l|}{ Fator 3: Sucesso e Eficiência (9,936\% da Variância) } \\
\hline As pessoas de sucesso nesta organização obedecem rigorosamente às políticas da organização. & 0,771 \\
\hline As pessoas de sucesso desta organização são aquelas que são corretas. & 0,720 \\
\hline A maneira mais eficiente é sempre o caminho correto nesta organização. & 0,717 \\
\hline $\begin{array}{l}\text { A principal responsabilidade das pessoas nesta organização é considerar a eficiência em primeiro } \\
\text { lugar. }\end{array}$ & 0,640 \\
\hline \multicolumn{2}{|l|}{ Fator 4: Instrumental (7,299\% da Variância) } \\
\hline Nesta organização, as pessoas valem mais por si mesmas. & 0,765 \\
\hline O trabalho é considerado inferior ao padrão, apenas quando afeta os interesses da organização. & 0,762 \\
\hline Nesta organização, as pessoas protegem seus próprios interesses acima de qualquer coisa. & 0,743 \\
\hline \multicolumn{2}{|l|}{ Total de Variância explicada: $65,517 \%$} \\
\hline \multicolumn{2}{|l|}{ Kaiser-Meyer-Olkin $(\mathrm{KMO})=0,844$} \\
\hline \multicolumn{2}{|l|}{ Teste de Esfericidade de Bartlett - Qui-quadrado=1.519,025; graus de liberdade=105; Significância=0,000. } \\
\hline
\end{tabular}

Os quatros fatores ou dimensões de clima ético que emergiram explicam $65,5 \%$ da variância dos dados originais. As dimensões obtidas são descritas a seguir, com indicação do critério ético de referência entre parênteses:

- Suporte (Benevolência): Explica 35,5\% da variância e compreende quatro dos seis fatores da dimensão Suporte descrita por Victor e Cullen (1988). Consequentemente foi nomeada da mesma forma.

- Regras, Leis e Códigos (Princípios): Explica uma parcela de $12,7 \%$ da variância e contêm dois itens da dimensão Regras e outros dois do fator Leis e Códigos descritos por Victor e Cullen. O nome da dimensão foi obtido da junção dos nomes dessas dimensões originais.

- Sucesso e Eficiência (Princípios): Explica uma parcela de 9,9\% da variância e reúne dois itens da dimensão Regras (critério ético de Princípios), um item do fator Suporte e outro do Instrumental obtidos por Victor e Cullen. Uma estrutura semelhante foi descrita por Shacklock, Manning e Hort (2011) em estudo sobre clima ético no setor público australiano e que chamaram a 
dimensão de Eficiência. Por isso, dada a presença de itens relacionados à palavra Sucesso e a semelhança indicada, o nome escolhido para dimensão foi Sucesso e Eficiência.

- Instrumental (Egoísmo): Explica uma parcela de 7,3\% da variância, agrupa três itens da dimensão Instrumental de Victor e Cullen e, portanto, foi chamada da mesma forma.

A dimensão predominante do clima ético entre os servidores foi a "Suporte", que explicou uma parcela de variância superior à soma das demais dimensões. Por outro lado o clima ético minoritário foi o "Instrumental". Esses resultados condizem com o que foi apontado por Cullen, Parboteeah e Victor (2003). Os outros dois climas observados tem ligação com o critério ético de princípios.

\subsection{Dimensões do Comprometimento Organizacional}

As dimensões do comprometimento organizacional foram obtidas da aplicação da técnica de análise fatorial exploratória com os dezoito itens do questionário. A análise revelou três dimensões ou tipos de comprometimento, assim como Meyer, Allen e Smith (1993). Na Tabela 2 são apresentados os resultados dessa análise.

As dimensões ou componentes do comprometimento organizacional obtidos também explicam $65,6 \%$ da variância dos dados originais. As três dimensões obtidas são descritas a seguir:

- Afetiva: Explica 37,8\% da variância e engloba três itens da sub-escala original proposta por Meyer, Allen e Smith (1993). Além destes, dois itens da sub-escala Normativa ("Eu devo muito a esta organização" e "Esta organização merece a minha lealdade") foram incluídos nessa dimensão revelando que esses itens são percebidos pelos participantes como relacionados à dimensão Afetiva.

- Normativa (ou moral): Explica 15,4\% da variância e reúne três itens da sub-escala original de Meyer, Allen e Smith.

- Calculativo (Instrumental ou de continuidade): Explica 12,4\% da variância e agrupa dois itens da sub-escala original de Meyer, Allen e Smith.

Estudos do CEPE [ISSN 1982-6729]. Santa Cruz do Sul, n. 42, p. 49-67, jan./jun. 2016. https://online.unisc.br/seer/index.php/cepe/index 
Tabela 2 - Resultados da Análise Fatorial do Comprometimento Organizacional

\begin{tabular}{|c|c|}
\hline Fatores e Itens & $\begin{array}{l}\text { Cargas } \\
\text { Fatoriais }\end{array}$ \\
\hline \multicolumn{2}{|l|}{ Fator 1: Comprometimento Afetivo (37,793\% da variância) } \\
\hline Esta organização tem grande significado pessoal para mim. & 0,782 \\
\hline Eu ficaria muito feliz em passar o resto da minha carreira nesta organização. & 0,699 \\
\hline Seria muito difícil para mim deixar... se eu quiser deixar esta organização. & 0,687 \\
\hline Eu devo muito a esta organização. & 0,661 \\
\hline Esta organização merece a minha lealdade. & 0,573 \\
\hline \multicolumn{2}{|l|}{ Fator 2: Comprometimento Normativo (15,366\% da variância) } \\
\hline Eu não deixaria esta organização agora, porque tenho um sentimento de obrigação. & 0,854 \\
\hline Eu me sentiria culpado se deixasse a organização agora. & 0,848 \\
\hline Mesmo sendo vantajoso para mim, eu não sinto que seria certo sair desta organização. & 0,801 \\
\hline \multicolumn{2}{|l|}{ Fator 3: Comprometimento Calculativo (12,446\% da variância) } \\
\hline Uma das poucas consequências negativas de sair da organização seriam as poucas alternativas. & 0,905 \\
\hline Eu acredito que tenho muito poucas opções para pensar em sair desta organização. & 0,874 \\
\hline \multicolumn{2}{|l|}{ Total de Variância explicada: 65,604\% } \\
\hline \multicolumn{2}{|l|}{ Kaiser-Meyer-Olkin $(\mathrm{KMO})=0,783$} \\
\hline \multicolumn{2}{|l|}{ Teste de Esfericidade de Bartlett - Qui-quadrado= 847,224; graus de liberdade=45; Significância=0,000. } \\
\hline
\end{tabular}

A dimensão "Afetiva" do comprometimento organizacional foi predominante e explicou um percentual de variância superior a soma das parcelas das demais sub-escalas. Em relação a esse componente, Menezes e Bastos (2011) afirmaram que desde o estudo de validação do modelo original em 1993, verificou-se que as dimensões "Afetiva" e "Normativa" apresentavam sobreposição conceitual. Desse modo, embora contenha os três componentes da teoria de Meyer e Allen, a sobreposição entre as duas dimensões revela que a estrutura fatorial obtida é diferente da original.

Diferenças como essa e até mesmo em número de componentes obtidos foram relatadas por Meyer et al (2012). Segundo os autores, essa diferença pode ser efeito da tradução dos itens do questionário, onde os termos originais podem ter significado diverso em outros idiomas afetando a compreensão da assertiva pelos participantes.

\subsection{Confiabilidade das Escalas Completas e Dimensões}

Foram realizadas análises de confiabilidade das escalas completas e dimensões do clima ético e comprometimento organizacional.

A medida de confiabilidade utilizada foi o coeficiente alfa de Cronbach ( $\alpha$ ). Segundo Hair et al. (2009), o alfa de Cronbach é a medida de confiabilidade mais amplamente utilizada e o limite inferior geralmente aceito é 0,7. A Tabela 3 apresenta os valores médios, desvios padrão e a de Cronbach das escalas e dimensões utilizadas neste estudo. 
Tabela 3 - Médias, Desvios Padrões e Coeficientes de Confiabilidade das Escalas e Dimensões

\begin{tabular}{lccc}
\hline \multicolumn{1}{c}{ Escalas e Dimensões } & Média & Desvio Padrão & $\boldsymbol{\alpha}$ de Cronbach \\
\hline Comprometimento (Completo) & 3,991 & 0,963 & 0,836 \\
Comprometimento Afetivo & 4,576 & 1,341 & 0,752 \\
Comprometimento Normativo & 2,625 & 1,588 & 0,841 \\
Comprometimento Calculativo & 3,347 & 1,706 & 0,782 \\
Clima Ético (Completo) & 3,570 & 0,477 & 0,745 \\
Clima Ético Suporte & 3,148 & 1,021 & 0,837 \\
Clima Ético Regras Leis e Códigos & 4,668 & 0,956 & 0,827 \\
Clima Ético Sucesso e Eficiência & 3,272 & 0,993 & 0,782 \\
Clima Ético Instrumental & 3,663 & 1,072 & 0,711 \\
\hline
\end{tabular}

Fonte: Elaborado pelos autores, 2015.

Todas as escalas e dimensões avaliadas foram consideradas confiáveis, tendo em vista os coeficientes $\alpha$ de Cronbach superiores a 0,7. A partir da Tabela 3 também é possível observar que o componente "Afetivo" do comprometimento organizacional e a dimensão "Regras, Leis e Códigos" do clima ético apresentaram os maiores valores médios.

\subsection{Influência do Clima Ético sobre o Comprometimento Organizacional}

O clima ético foi estudado como antecedente do comprometimento organizacional. Para testar esse relacionamento foram realizadas análises de regressão múltiplas com base nos valores dos escores fatoriais das dimensões do clima ético e do comprometimento.

A análise foi realizada com o uso de dois métodos: Enter - para avaliar a influência de todas as dimensões de clima ético sobre cada componente do comprometimento organizacional; e, Stepwise - para apontar o modelo que melhor representa a influência do clima ético sobre cada componente do comprometimento organizacional.

Em virtude da existência de três componentes do comprometimento organizacional, as análises de regressão múltipla foram realizadas em três etapas: o clima ético como antecedente dos comprometimentos (1) "Afetivo", (2) "Normativo" e (3) "Calculativo".

Na primeira etapa buscou-se responder a pergunta: O clima ético afeta o comprometimento organizacional "Afetivo"? Os resultados das análises de regressão múltipla são apresentados na Tabela 4.

Estudos do CEPE [ISSN 1982-6729]. Santa Cruz do Sul, n. 42, p. 49-67, jan./jun. 2016. https://online.unisc.br/seer/index.php/cepe/index 
Tabela 4 - Resultados das Análises de Regressão Múltiplas para Clima Ético e Comprometimento Afetivo

\begin{tabular}{|c|c|c|c|c|c|c|}
\hline \multirow{2}{*}{ Método } & \multirow{2}{*}{$\begin{array}{c}\text { Variável Independente } \\
\text { Climas Éticos }\end{array}$} & \multicolumn{2}{|c|}{ Ajuste do Modelo } & \multirow{2}{*}{$\begin{array}{c}\text { ANOVA } \\
\text { F } \\
\text { (Sign.) }\end{array}$} & \multicolumn{2}{|c|}{ Coeficientes } \\
\hline & & $\mathbf{R}^{2}$ & $\mathbf{R}^{2}$ ajustado & & $\begin{array}{c}\alpha \\
\text { (Sign.) }\end{array}$ & $\beta$ (Sign.) \\
\hline Enter & $\begin{array}{l}\text { (1) Suporte } \\
\text { (2) Regras, Leis e } \\
\text { Códigos } \\
\text { (3) Sucesso e Eficiência } \\
\text { (4) Instrumental }\end{array}$ & 0,107 & 0,092 & $\begin{array}{c}7,264 \\
(0,000)\end{array}$ & $\begin{array}{c}6,02 \times 10^{-17} \\
(1,000)\end{array}$ & $\begin{array}{c}0,182(0,003) \\
0,241(0,000) \\
0,094(0,122) \\
-0,084(0,166)\end{array}$ \\
\hline $\begin{array}{l}\text { Stepwis } \\
\text { e }\end{array}$ & $\begin{array}{l}\text { (1) Regras, Leis e } \\
\text { Códigos } \\
\text { (2) Suporte }\end{array}$ & 0,091 & 0,083 & $\begin{array}{l}12,242 \\
(0,000)\end{array}$ & $\begin{array}{c}6,95 \times 10^{-17} \\
(1,000)\end{array}$ & $\begin{array}{l}0,241(0,000) \\
0,182(0,003)\end{array}$ \\
\hline
\end{tabular}

Com o primeiro método (Enter), verificou-se que o modelo que considera as quatro dimensões do clima ético conjuntamente é significante (Sign. $F=0,000$ ) e explica $10,7 \%$ da variância do comprometimento "Afetivo". No entanto, apenas as dimensões "Suporte" e "Regras, Leis e Códigos" apresentaram relação significante e positiva $(\beta 1=0,182 ; \beta 2=0,241 ; p$-valor $<0,05)$ com o componente avaliado. As dimensões "Sucesso e Eficiência" e "Instrumental" não tiveram relação significante com a variável dependente, mas a primeira indicou influência positiva, enquanto a segunda mostrou-se negativamente relacionada.

Esse resultado foi confirmado com o uso do método Stepwise que apontou que o modelo mais adequado para representar a relação entre o clima ético e o comprometimento "Afetivo", envolve as dimensões "Suporte" e "Regras, Leis e Códigos". O modelo gerado pelo segundo método (Stepwise) explicou 9,1\% da variância do componente "Afetivo".

Dessa forma, a resposta à pergunta feita é positiva, ou seja, o clima ético afeta o comprometimento Afetivo, com destaque para a influência conjunta das dimensões "Regras, "Leis e Códigos" e "Suporte".

$\mathrm{Na}$ segunda etapa a pretensão foi verificar se o clima ético afeta o comprometimento organizacional "Normativo". Desse modo, os resultados das análises de regressão múltipla são apresentados na Tabela 5. O primeiro método (Enter) aplicado gerou um modelo não significante (Sign. $F=0,149$ ). 
Tabela 5 - Resultados das Análises de Regressão Múltiplas para Clima Ético e Comprometimento Normativo

\begin{tabular}{|c|c|c|c|c|c|c|}
\hline \multirow{2}{*}{ Método } & \multirow{2}{*}{$\begin{array}{c}\text { Variável Independente } \\
\text { Climas Éticos }\end{array}$} & \multicolumn{2}{|c|}{ Ajuste do Modelo } & \multirow{2}{*}{$\begin{array}{c}\text { ANOVA } \\
\mathrm{F} \\
\text { (Sign.) }\end{array}$} & \multicolumn{2}{|c|}{ Coeficientes } \\
\hline & & $\mathbf{R}^{2}$ & $R^{2}$ ajustado & & $\begin{array}{c}\alpha \\
\text { (Sign.) }\end{array}$ & $\beta$ (Sign.) \\
\hline \multirow{5}{*}{ Enter } & (1) Suporte & \multirow{5}{*}{0,027} & \multirow{5}{*}{0,011} & \multirow{5}{*}{$\begin{array}{c}1,707 \\
(0,149)\end{array}$} & \multirow{5}{*}{$\begin{array}{c}-1,63 \times 10^{-17} \\
(1,000)\end{array}$} & $0,063(0,318)$ \\
\hline & (2) Regras, Leis e & & & & & $-0,012(0,848)$ \\
\hline & & & & & & $0,141(0,026)$ \\
\hline & (3) sucesso e Eticlencla & & & & & $-0,057(0,371)$ \\
\hline & (4) Instrumental & & & & & \\
\hline $\begin{array}{l}\text { Stepwis } \\
\text { e }\end{array}$ & (1) Sucesso e Eficiência & 0,020 & 0,016 & $\begin{array}{c}5,012 \\
(0,026)\end{array}$ & $\begin{array}{c}1,77 \times 10^{-17} \\
(1,000)\end{array}$ & $0,141(0,026)$ \\
\hline
\end{tabular}

Nota: $\alpha$ - Intercepto. $\beta$ - Coeficiente angular da variável independente. Significância: $5 \%$ (p-valor <0,05).

Fonte: Elaborado pelos autores, 2015.

Na sequência foi utilizado o método Stepwise e o modelo gerado indicou que o melhor ajuste para representar o efeito do clima ético sobre o comprometimento "Normativo" envolve somente a dimensão "Sucesso e Eficiência". O referido modelo é significante (Sign. F = 0,026), explica 2,0\% da variância do componente "Normativo" e indica uma relação positiva e significante $\left(\beta_{1}=0,141 ; p\right.$-valor $=0,026)$ entre a variável explicativa e a dependente.

Diante desses resultados, contatou-se que o clima ético (a dimensão "Sucesso e Eficiência") afeta o comprometimento "Normativo".

$\mathrm{Na}$ terceira etapa foi verificado se o clima ético afeta o comprometimento organizacional "Calculativo". Os resultados das análises de regressão múltipla relativas a essa etapa são apresentados na Tabela 6.

Com o método Enter, verificou-se que o clima ético influencia o comprometimento "Instrumental", tendo em vista que o modelo gerado é significante (Sign. $F=0,020$ ) e explica $4,7 \%$ da variância da variável dependente.

Dentre as dimensões do clima ético, somente uma ("Regras, Leis e Códigos"; $\beta_{1}=0,159$ ) pode ser considera significante ( $p$-valor $=0,012$ ) para explicar a variação do comprometimento "Calculativo". Além dessa dimensão, o clima "Sucesso e Eficiência" $\left(\beta_{3}=0,083\right)$ também tem relação positiva com o componente "Calculativo", por outro lado as demais dimensões - "Suporte" $\left(\beta_{1}=-0,119\right)$ e "Instrumental" $\left(\beta_{4}=-0,020\right)$ - possuem relação negativa. 
Tabela 6 - Resultados das Análises de Regressão Múltiplas para Clima Ético e Comprometimento Calculativo

\begin{tabular}{|c|c|c|c|c|c|c|}
\hline \multirow{2}{*}{ Método } & \multirow{2}{*}{$\begin{array}{c}\text { Variável Independente } \\
\text { Climas Éticos }\end{array}$} & \multicolumn{2}{|c|}{ Ajuste do Modelo } & \multirow{2}{*}{$\begin{array}{c}\text { ANOVA } \\
\text { F } \\
\text { (Sign.) }\end{array}$} & \multicolumn{2}{|c|}{ Coeficientes } \\
\hline & & $\mathbf{R}^{2}$ & $R^{2}$ ajustado & & $\begin{array}{c}\alpha \\
\text { (Sign.) }\end{array}$ & $\beta$ (Sign.) \\
\hline \multirow{5}{*}{ Enter } & (1) Suporte & \multirow{5}{*}{0,047} & \multirow{5}{*}{0,031} & \multirow{5}{*}{$\begin{array}{c}2,977 \\
(0,020)\end{array}$} & \multirow{5}{*}{$\begin{array}{c}-7,15 \times 10^{-17} \\
(1,000)\end{array}$} & $-0.119(0.059)$ \\
\hline & (2) Regras, Leis e & & & & & $0,159(0,012)$ \\
\hline & \multirow{3}{*}{$\begin{array}{l}\text { (3) Sucesso e Eficiência } \\
\text { (4) Instrumental }\end{array}$} & & & & & $0.083(0.188)$ \\
\hline & & & & & & \\
\hline & & & & & & 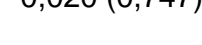 \\
\hline Stepwis & (1) Regras, Leis e & (2050 & (1) & 6,405 & $-7,99 \times 10^{-17}$ & $0150(0010$ \\
\hline$e$ & Códigos & $0,0<0$ & $0,0<1$ & $(0,012)$ & $(1,000)$ & $0,159(0,012)$ \\
\hline
\end{tabular}

Nota: $\alpha$ - Intercepto. $\beta$ - Coeficiente angular da variável independente. Significância: $5 \%$ (p-valor <0,05).

Fonte: Elaborado pelos autores, 2015.

Por sua vez, o método Stepwise apontou que a melhor representação da influência do clima ético sobre o comprometimento "Calculativo" envolvendo somente a dimensão "Regras, Leis e Códigos" $\left(\beta_{1}=0,159\right)$ é significante (Sign. $\left.F=0,012\right)$ e explica $2,5 \%$ da variância. Desse modo foi confirmado que o clima ético, especialmente, a dimensão "Regras, Leis e Códigos", afeta o comprometimento "Calculativo".

A partir dos resultados das três etapas foi confirmada a influência do clima ético sobre o comprometimento organizacional. A dimensão "Suporte" do clima ético apresentou influência significante e positiva sobre o componente "Afetivo" do comprometimento organizacional. Já o clima ético "Regras, Leis e Códigos" afetou as dimensões "Afetiva" e "Calculativa" do comprometimento. O clima ético "Sucesso e Eficiência" mostrou-se um antecedente significante e de influência positiva sobre o comprometimento "Normativo". Por sua vez, o clima ético "Instrumental" não apresentou influência significante sobre qualquer componente do comprometimento organizacional.

Além da confirmação da influência do clima ético no comprometimento organizacional, podese observar que neste estudo um dos climas de princípios, a dimensão "Sucesso e Eficiência", influenciou positivamente todos os componentes do comprometimento organizacional, concordando com os resultados de Cullen, Parboteeah e Victor (2003) e Tsai e Huang (2008).

O clima "Regras, Leis e Códigos" (de princípios) afetou negativamente o componente "Normativo" e positivamente as dimensões "Afetiva" e "Calculativa" do comprometimento organizacional. Já o clima egoísta (dimensão "Instrumental") afetou negativamente as dimensões do comprometimento, o que também foi relatado por Cullen, Parboteeah e Victor (2003) e Tsai e Huang (2008).

O clima benevolente (dimensão "Suporte"), por sua vez, afetou positivamente os comprometimentos "Afetivo e Normativo", mas negativamente o componente "Calculativo". Esses resultados também concordam, mesmo que parcialmente quanto à dimensão Calculativa, com estudos de Cullen, Parboteeah e Victor (2003), Tsai e Huang (2008) e Filipova (2009). 


\section{CONSIDERAÇÕES FINAIS}

Inicialmente foram investigadas as dimensões latentes do clima ético e do comprometimento organizacional ligadas aos ambientes de trabalho dos participantes. Foram identificadas quatro dimensões do clima ético ("Suporte", "Regras, Leis e códigos", "Sucesso e Eficiência" e "Instrumental") e três dimensões do comprometimento organizacional ("Afetiva", "Normativa" e "Calculativa"), de forma consistente com obtido por Meyer, Allen e Smith (1993).

Foi observado que as dimensões "Suporte" e "Regras, leis e códigos" do clima ético influenciam positivamente a dimensão "Afetiva" do comprometimento organizacional. Constatou-se também que a dimensão "Sucesso e Eficiência" do clima ético influencia positivamente o comprometimento organizacional "Normativo". Já a dimensão "Calculativa" do comprometimento foi influenciada positivamente pelo clima ético "Regras, leis e códigos".

Além dessas constatações foi possível observar neste estudo que os climas éticos de princípios (dimensões "Regras, Leis e Códigos" e "Sucesso e Eficiência") influenciaram positivamente todos os componentes do comprometimento organizacional, enquanto o clima egoísta (dimensão "Instrumental") afetou negativamente. O clima benevolente (dimensão "Suporte"), por sua vez, afetou positivamente os comprometimentos "Afetivo" e "Normativo", mas negativamente o componente "Calculativo", concordando com diversos estudos da área.

Com os resultados obtidos na pesquisa é possível afirmar que os objetivos da pesquisa foram alcançados e a possibilidade de aumentar o comprometimento organizacional através do gerenciamento do clima ético tornou-se mais clara e consistente. E assim, o comprometimento organizacional como um instrumento confiável de previsão de comportamentos poderá ser usado como ferramenta para diminuir o absenteísmo e a rotatividade, e ainda aumentar a satisfação, o desempenho e a adaptabilidade do servidor.

Para pesquisas futuras, sugere-se a aplicação do modelo adotado neste estudo em toda a organização visando comprovar sua validade para a população e identificar grupos ou áreas onde predomina determinada dimensão do clima ético para definição de estratégias para melhoria do comprometimento organizacional.

\section{REFERÊNCIAS}

ABELSON, M. A. The Impact of Goal Change on Permanent Perceptions and Behaviors of Employees. Journal of Management, v. 9, n. 1, p. 65-79, 1983.

ALLEN, N. J.; MEYER, J. P. The measurement and antecedents of affective, continuance and normative commitment to the organization. Journal of Occupational Psychology, v. 63, n. 1, p. 1-18, 1990.

ANGLE, H. L.; PERRY, J. L. An Empirical Assessment of Organizational Commitment and Organizational Effectiveness. Administrative Science Quarterly, v. 26, n. 1, p. 1-14, 1981

BABIN, B. J.; BOLES, J. S.; ROBIN, D. P. Representing the perceived ethical work climate among marketing employees. Journal of the Academy of Marketing Science, v. 28, n. 3, p. 345-358, 2000.

COHEN, J.; COHEN, P.; WEST, S. G.; AIKEN, L. S. Applied multiple regression/correlation analysis for the behavioral sciences. 3. ed., Mahwah, NJ: Erlbaum, 2003. 
CULLEN, J. B.; PARBOTEEAH, K. P.; VICTOR, B. The Effects of Ethical Climates on Organizational Commitment: A Two-Study Analysis. Journal of Business Ethics, v. 46, n. 2, p. 127-141, 2003.

ELCI, M.; ALPKAN, L. The Impact of Perceived Organizational Ethical Climate on Work Satisfaction. Journal of Business Ethics, v. 84, n. 3, p. 297-311, 2009.

ERBEN, G. S.; GUNESER, A. B. The Relationship Between Paternalistic Leadership and Organizational Commitment: Investigating the Role of Climate Regarding Ethics. Journal of Business Ethics, v. 82, n. 4, p. 955-968, 2008.

FILIPOVA, A. A. Licensed Nurses' Perceptions of Ethical Climates in Skilled Nursing Facilities. Nursing Ethics, v. 16, n. 5, p. 574-588, 2009.

HAIR, J. F., JR.; BLACK, W. C.; BABIN, B. J.; ANDERSON, R. E.; TATHAM, R. L. Análise Multivariada de Dados. 6를. ed., Porto Alegre: Bookman, 2009.

HAMMER, T.; LANDAU, J.; STERN, R. Absenteeism When Workers Have a Voice: The Case of Employee Ownership. Journal of Applied Psychology, v. 66, n. 5, p. 561-573, 1981.

HERNDON, N. C., JR; FRAEDRICH J. P.; YEH, Q. An Investigation of Moral Values and the Ethical Content of the Corporate Culture: Taiwanese Versus U.S. Sales People. Journal of Business Ethics, v. 30, n. 1, p. 73-85, 2001.

HUNT, S. D.; CHONKO, L. B.; WOOD, V. R. Organizational Commitment and Marketing. Journal of Marketing, v. 49, n. 1, p. 112-126, 1985.

MARTIN, K. D.; CULLEN, J. B. Continuities and Extensions of Ethical Climate Theory: A MetaAnalytic Review. Journal of Business Ethics, v. 69, n. 2, p. 175-194, 2006.

MAYER, D. M.; KUENZI, M.; GREENBAUM, R. L. Making Ethical Climate a Mainstream Management Topic: A Review, Critique, and Prescription for the Empirical Research on Ethical Climate. In: CREMER, D. (Ed.), Psychological perspectives on ethical behavior and decision making. Greenwich, CT: Information Age Publishing, 2009.

MENDES, A. V. C.; ANDRADE, H. D., JR. Administração pública federal: a percepção de servidores sobre a ética. Acta Scientiarum. Human and Social Sciences, v. 32, n. 2, p. 115-125, 2010.

MENEZES, I. G.; BASTOS, A. V. B. Comprometimento organizacional atitudinal: um estudo empírico sobre a dimensionalidade do construto. Estudos de Psicologia, v. 28, n. 4, p. 463-474, 2011.

MEYER, J. P.; ALLEN, N. J. Testing the "side-bet theory" of organizational commitment: Some methodological considerations. Journal of Applied Psychology, v. 69, n. 3, p. 372-378, 1984.

MEYER, J. P.; ALLEN, N. J. A Three-Component Conceptualization of Organizational Commitment. Human Resource management Review, v. 1, n. 1, p. 61-89, 1991.

MEYER, J. P.; ALLEN, N. J. Commitment in the workplace: Theory, research, and application. Thousand Oaks, CA: Sage, 1997.

MEYER, J. P.; ALLEN, N. J.; SMITH, C. A. Commitment to organizations and occupations: Extension and test of a three-component conceptualization. Journal of Applied Psychology, v. 78, n. 4, p. 538$551,1993$.

MEYER, J. P.; STANLEY, D. J.; JACKSON, T. A.; MCINNIS, K. J.; MALTIN, E. R.; SHEPPARD, L. Affective, normative, and continuance commitment levels across cultures: A meta-analysis. Journal of Vocational Behavior, v. 80, n. 2, p. 225-245, 2012.

MORRIS, J.; SHERMAN, J. D. Generalizability of Organizational Commitment Model. Academy of Management Journal, v. 24, n. 3, p. 512-526, 1981.

MULKI, J. P.; JARAMILLO, J. F.; LOCANDER, W. B. Effect of Ethical Climate on Turnover Intention: Linking Attitudinal- and Stress. Journal of Business Ethics, v. 78, n. 4, p. 559-574, 2008.

RANDALL, D. M. Commitment and the Organization: The Organization Man Revisited. Academy of Management Review, v. 12, n. 3, p. 460-471, 1987.

SHACKLOCK, A.; MANNING, M.; HORT, L. Dimensions and types of Ethical Climate within Public Sector Human Resource Management. Journal of New Business Ideas \& Trends, v. 9, n. 1, p. 51-66, 2011. 
SCHUMACKER, R. E.; LOMAX, R. G. A Beginner's Guide to Structural Equation Modeling. 2 ed., Mahwah, NJ: Lawrence Erlbaum Associates, 2004.

SCHWEPKER, C. H., JR. Understanding Salespeople's Intention to Behave Unethically: The Effects of Perceived Competitive Intensity, Cognitive Moral Development and Moral Judgment. Journal of Business Ethics, v. 21, n. 4, p. 303-316, 1999.

SCHWEPKER, C. H., JR. Ethical Climate's Relationship to Job Satisfaction, Organizational Commitment, and Turnover Intention in the Salesforce. Journal of Business Research, v. 54, n. 1, p. 39-52, 2001.

SIMS, R. I.; KROECK, G. K. The Influence of Ethical Fit on Employee Satisfaction, Commitment and Turnover. Journal of Business Ethics, v. 13, n. 12, p. 939-947, 1994.

TREVIÑO, L. K.; BROWN, M. E. Managing to be Ethical: Debunking Five Business Ethics Myths. Academy of Management Executive, v. 18, n. 2, p. 69-81, 2004.

TSAI, M.; HUANG, C. The Relationship among Ethical Climate Types, Facets of Job Satisfaction, and the Three Components of Organizational Commitment: A Study of Nurses in Taiwan. Journal of Business Ethics, v. 80, n. 3, p. 565-581, 2008

VALENTINE, S.; GODKIN, L.; LUCERO, M. Ethical Context, Organizational Commitment, and PersonOrganization Fit. Journal of Business Ethics, v. 41, n. 4, p. 349-360, 2002.

VICTOR, B.; CULLEN, J. B. A theory and measure of ethical climate in organizations. Research in Corporate Social Performance and Policy, v. 9, p. 51-71, 1987.

VICTOR, B.; CULLEN, J. B. The Organizational Bases of Ethical Work Climates. Administrative Science Quarterly, v. 33, n. 1, p. 101-125, 1988.

YENER, M.; YALDIRAN, M.; ERGUN, S. The Effect of Ethical Climate on Work Engagement. Procedia-Social and Behavioral Sciences, v. 58, p. 724-733, 2012.

WIMBUSH, J. C.; SHEPARD, J. M.; MARKHAM, S. M. An empirical examination of the relationship between ethical climate and ethical behavior from multiple level of analysis. Journal of Business Ethics, v. 16, n. 16, p. 1705-1716, 1997. 